\title{
Revisitando o "Barba Azul” (1697) através das imagens silenciosas de Georges Méliès
}

\author{
Maristela Gonçalves Sousa Machado ${ }^{i}$ \\ Ana Luiza Ramazzina-Ghirardi ${ }^{\text {ii }}$
}

\section{RESUMO}

Este artigo propõe uma sequência didática baseada em aspectos das relações entre a narrativa escrita do conto "Barba Azul" (1697) de Charles Perrault e a versão fílmica homônima de Georges Méliès (1901). Em um primeiro momento, analisaremos algumas questões relativas ao processo de transposição midiática (RAJEWSKYY, 2012) do conto para o filme. Em seguida, proporemos a sequência didática (DOLZ, NOVERRAZ e SCHNEUWLY, 2004) baseada na relação intermidiática entre essas duas versões. O resultado esperado é o de que os futuros formadores em Letras adquiram um novo letramento no campo da intermidialidade, que os torne aptos a analisar, de maneira fundamentada, as novas configurações textuais produzidas em diversos produtos de mídia conforme preconiza a Base Nacional Comum Curricular de 2018.

Palavras-chave: Barba Azul; Conto de fadas; Versão fílmica; Transposição midiática; Sequência didática.

\begin{abstract}
This article proposes a teaching sequence based on aspects of the relations between Charles Perrault's fairy tale "Blue Beard" (1697) and the homonymous film adaptation by Georges Méliès (1901). Initially, we analyze topics related to the intermedial transposition process (RAJEWSKY, 2012) from the tale to the film version. Afterwards, we propose a teaching sequence (DOLZ; NOVERRAZ; SCHNEUWLY, 2004) based on the intermedial relation between these two versions. The expected outcome is that the teachers-to-be majoring in Arts, and Languages and Literature acquire a new literacy, enabling them to analyze different textual configurations produced in several media products, as advocated by the 2018 National Common Curricular Base.
\end{abstract}

Keywords: Blue Beard; Fairy tale; Film version; Intermedial transposition; Teaching sequence.

\footnotetext{
${ }^{i}$ Professora associada da área de Francês do Centro de Letras e Comunicação da Universidade Federal de Pelotas. ORCID: http://orcid.org/0000-0001-8389-1213/ maristelagsm@ gmail.com

ii Professora Associada do departamento de Letras da UNIFESP e credenciada no Programa de PósGraduação em Letras da mesma instituição. https://orcid.org/0000-0002-5860-5198/ amazzina@unifesp.br
} 
Leia "ele entrou na sala" e imagine mil encenações. Veja "ele entrou na sala" no cinema como o conhecemos e você ficará limitado a uma única encenação. $\mathrm{O}$ que você lembra de um bom filme - e vamos falar apenas de bons filmes - não é uma história, mas uma experiência especial e quem sabe única que tem a ver com a atmosfera, ambiência, performance, estilo, uma atitude emocional, gestos, fatos isolados, uma experiência audiovisual específica que não depende da história (Peter Greenaway, 2001).

\section{CONSIDERAÇÕES INICIAIS}

Com o advento da era digital e a ascensão do apelo da linguagem visual, os paradigmas educacionais vêm sofrendo modificações importantes, sendo essencial que os estudos de novas configurações textuais sejam contemplados pelos currículos escolares. Segundo Fusillo (2013), no caso dos estudos literários, é preciso considerar que a hegemonia da escrita está sendo colocada em perspectiva e o próprio status da literatura como um campo superior e circunscrito, vem dando lugar a um domínio mais fluido e difuso. Pesquisas no campo da intermidialidade, bem como o uso crescente de conceitos literários fulcrais, como narrativa e retórica, em outras Ciências tais como história, sociologia, antropologia e psicanálise, evidenciam essa nova perspectiva.

No atual contexto de grande variedade de modalidades textuais predominantemente visuais, motivar os jovens para a leitura de obras literárias tornou-se um desafio para os professores. Não que o interesse pela leitura não exista; é frequente a participação dos jovens em manifestações como saraus, canais de booktubers, fanfics e slam - uma batalha de poesia falada que chegou à Festa Literária de Paraty de 2019.

A $5^{\text {a }}$ edição da pesquisa Retratos da Leitura do Brasil, realizada pelo Instituto Pró Livro e aplicada em 2019-2020, revelou que entre os entrevistados que afirmam gostar muito de ler estão os adultos com curso superior e melhor situação econômica, seguidos por crianças e jovens, sendo a faixa etária entre 5 e 10 anos a que tem o maior percentual (46\%) dos que afirmam gostar muito muito de ler.

A revelação de que quase a metade das crianças gosta muito de ler traz esperança e inquietação: por que a partir dos 18 anos o percentual de quem não gosta de ler aumenta de forma acentuada, passando de $3 \%$ a $20 \%$ ? O que estamos deixando de fazer ou onde estamos errando, em especial quando 
esses jovens concluem o Fundamental II e chegam ao Ensino Médio? (FAILLA, 2021; grifo do autor).

Failla faz uma constatação que oferece pistas para repensar e incrementar práticas de leitura em faixas etárias nevrálgicas a essa realidade. Ao considerar o ensino superior de Letras um campo estratégico para lidar com essa questão, este artigo relata uma pesquisa com objetivo de adotar uma perspectiva literária da intermidialidade na elaboração de materiais visando a formação de leitores literários, no contexto da formação de professores da área de Letras. Neste artigo, propomos uma sequência didática (DOLZ; NOVERRAZ; SCHNEUWLY, 2004) para a leitura de "Barba Azul" (1697), conto de fadas de Charles Perrault e de sua transposição midiática (RAJEWSKY, 2012) realizada por Georges Méliès em 1901, de forma a contribuir também para a construção de um repertório cultural transdisciplinar.

Na seção 1, um rápido olhar sobre alguns documentos do MEC trará uma ideia da evolução das orientações oficiais para o ensino-aprendizagem de Literatura e outras linguagens. Na seção 2, justificaremos a escolha do corpus para a elaboração de uma sequência didática e apresentaremos o conto de Charles Perrault. Discutiremos o filme de Georges Méliès, na seção 3 e a transposição midiática, segundo Rajewsky (2012), na seção 4. Na seção 5, apresentaremos um sequência didática visando contribuir para a formação de futuros formadores em Letras. Nas considerações finais, retomaremos nossa proposta de sequência didática, enfatizando a importância da capacitação dos licenciandos em Letras para a realização de atividades centradas em adaptações de textos literários.

\section{SOBRE OS DOCUMENTOS OFICIAIS}

No contexto atual da sociedade contemporânea, mudanças no ensino da literatura tornam-se necessárias. É preciso levar em conta o imaginário dos novos leitores, criando conexões entre seu conhecimento de mundo, suas práticas de leitura e os textos literários. Vejamos, a seguir, como evoluiu o discurso de alguns documentos oficiais sobre a inclusão de outras linguagens e semioses nos currículos escolares brasileiros.

Os Parâmetros Curriculares Nacionais para o Ensino Médio de 2000 reconhecem que "No campo dos sistemas de linguagem, podemos delimitar a linguagem verbal e 
não-verbal e seus cruzamentos verbo-visuais, audiovisuais, áudio-verbo-visuais etc." (BRASIL, 2000, p.6). A possibilidade do uso de novas tecnologias também é apontada:

\begin{abstract}
A questão das sociedades letradas, da constituição do campo artístico, das novas tecnologias [...] pode ser uma abordagem de interesse para todas as disciplinas da área de Linguagens, Códigos e suas Tecnologias, bem como o estudo da inter-relação produção/recepção (BRASIL, 2000, p. 7).
\end{abstract}

Em 2006, nas Orientações Curriculares para o Ensino Médio há finalmente uma abertura do texto literário para outras artes com ressalvas:

Também é desejável adotar uma perspectiva multicultural, em que a Literatura obtenha a parceria de outras áreas, sobretudo artes plásticas e cinema, não de um modo simplista, diluindo as fronteiras entre elas e substituindo uma coisa por outra, mas mantendo as especificidades e o modo de ser de cada uma delas [...]. (BRASIL, 2006, p. 74).

A mudança significativa quanto à presença de conhecimentos referentes a "diferentes linguagens ou semioses" se manifestou no mais recente documento normativo da educação brasileira, a Base Nacional Comum Curricular de 2018, referencial de todos os currículos de todas as redes públicas e particulares. No que tange a Língua Portuguesa, a BNCC para o Ensino Médio determina que, embora a cultura da palavra escrita tenha primazia na educação escolar, "é preciso considerar a cultura digital, os multiletramentos e os novos letramentos, entre outras denominações que procuram designar novas práticas sociais e de linguagem” (BRASIL, 2018, p. 487).

No campo artístico-literário, prescreve-se a análise contextualizada e mais fundamentada de produções artísticas e dos textos literários, com destaque para os clássicos e para outras "formas de apropriação do texto literário, de produções cinematográficas e teatrais e de outras manifestações artísticas (remidiações, paródias, estilizações, videominutos, fanfics etc.)"(BRASIL, 2018, p. 503).

A leitura da BNCC provoca vários questionamentos, desde os mais básicos sobre as condições materiais das escolas públicas até o perfil dos egressos dos cursos de licenciatura em Letras. Com essas propostas, um questionamento surge: a formação atual os torna habilitados a promover a aprendizagem da literatura pelo viés dessas novas práticas? Não se trata de uma facilitação ou substituição da leitura do texto literário, mas de trabalhar com abordagens que levem em consideração a forte presença 
da imagem e das novas tecnologias midiáticas em nossa sociedade, tornando o texto mais atraente e próximo do universo do leitor, sensibilizando-o para a possibilidade de criação de novos sentidos para textos canônicos.

A resposta poderia estar na reformulação dos Projetos Pedagógicos de Curso das Licenciaturas em Letras Português e Francês (PPCs) de cada universidade, no esforço de atualizar as Diretrizes Curriculares Nacionais dos Cursos de Letras que datam de 2001. Estas determinam sucintamente que "o objetivo do Curso de Letras é formar profissionais interculturalmente competentes, capazes de lidar, de forma crítica, com as linguagens, especialmente a verbal, nos contextos oral e escrito", devendo para tanto "ser capaz de refletir teoricamente sobre a linguagem, de fazer uso de novas tecnologias" (BRASIL, 2001, p. 30).

Pretendemos contribuir para a reflexão sobre as relações entre os Estudos de Intermidialidade e o ensino-aprendizagem, estimulando a inclusão da leitura das diferentes formas de apropriação dos textos literários nas ementas das disciplinas da dupla licenciatura de Letras na formação do docente de línguas. Buscar formas de estimular e incrementar a prática de leitura não é uma inquietação isolada de nossa pesquisa. É possível citar vários movimentos que estimulam debates em torno do assunto como, por exemplo, o número especial da revista Synergies, Vers les productions multimodales et intermédiales, organizado por Ramazzina-Ghirardi e Lacelle (2018), e, mais especificamente, os artigos abordando a formação do leitor proficiente em língua estrangeira (RAMAZZINA-GHIRARDI, 2017 e 2018; RAMAZZINA-GHIRARDI; PINHEIRO, 2020).

\section{A ESCOLHA DO TEXTO FONTE}

O primeiro passo para a elaboração de um roteiro de ensino-aprendizagem visando a formação de leitores autônomos de adaptações de textos literários é a escolha do corpus. Fomos motivadas primeiramente pelo potencial de renovação e maleabilidade que os contos de fadas vêm mantendo ao longo dos séculos. Como Maria Rita Kehl, acreditamos que "o atual império das imagens não retirou a força das narrativas orais" (KEHL, 2006, p. 16), mas questionamos a sua ideia de que o apelo à 
imaginação e a conexão com o caráter maravilhoso se devem justamente à ausência de imagens visuais na transmissão oral através da leitura.

Nos últimos dez anos, um número expressivo de filmes comprova a popularidade dos contos de fadas e o interesse dos grandes estúdios hollywoodianos pelo gênero. ${ }^{1}$ Sua magia parece se confundir com a do próprio cinema por sua dimensão onírica, apelo ao inconsciente, vocação popular e gosto pelas narrativas iniciáticas de heróis e heroínas que habitam o imaginário coletivo. A qualidade extraordinária das imagens digitais potencializou essa magia, assim como o desencanto com o tempo presente e com a degradação do planeta, em um movimento que faz lembrar a popularidade dos contos de fadas alavancada pelos românticos no conturbado século XIX francês.

Quanto à escolha específica de "Barba Azul" de Charles Perrault como textofonte, parece-nos interessante explorar um conto de fadas escrito no século XVII que se tornou um fenômeno editorial no Brasil. Entre traduções literárias novas e reeditadas, e recriações do conto, foram quinze edições, ${ }^{2}$ uma delas, A história do barba azul, de Antônio Klévisson Viana (Escala Educacional, 2008), adaptação para o cordel.

A reativação do conto de Perrault acontece desde sua publicação em 1697; segundo Jack Zipes (2013, p. 72), "Barba Azul" foi adaptado com uma frequência incomum para chapbooks e representações teatrais, sendo traduzido em diferentes línguas europeias. Ao longo dos quatro últimos séculos, o conto foi reconfigurado inúmeras vezes: ópera, teatro, cartazes, postais, poesia, rádio, romance, livros infantis, histórias em quadrinhos, cinema, fotografia, pintura, televisão e representações numéricas na Internet.

Exemplos da presença do conto de Charles Perrault na contemporaneidade encontram-se nas interpretações psicanalíticas constantemente reeditadas. ${ }^{3}$ Jogos de RPG, videogames, histórias em quadrinhos e mangás fazem reviver o personagem no universo infantojuvenil. Permanência, criação e metamorfose na circulação e recepção do "Barba Azul" de Perrault vêm resultando em novas leituras que conferem ao conto uma grande visibilidade na contemporaneidade.

\section{O TEXTO-FONTE: UM CONTO DE ANTIGAMENTE}


"Barba Azul" foi publicado em Histórias do tempo antigo com moralidades ou Contos de Mamãe Gansa (1697), juntamente com "A Bela adormecida no bosque”, "O Chapeuzinho vermelho", "O Gato de botas", "As Fadas", “A Gata Borralheira", "Riquete do topete" e "O Pequeno Polegar". Considerados um divertimento mundano dos salões, os contos de fadas estavam na moda e eram escritos, em sua maior parte, por mulheres, sendo Madame d'Aulnoy considerada a iniciadora do conto de fadas literário em 1760.

Charles Perrault (1628-1703) rompe com essa tendência e, com uma atitude audaciosa para um membro da Academia Francesa, declara-se caudatário da tradição oral mais popular dos contos do tipo que se ouvia das governantas e avós, muitas vezes inspirados por velhas histórias orientais e medievais. Perrault escreve seus Contos de Mamãe Gansa em estilo límpido e sem artifícios retóricos, mas com a arte e a sobriedade que refletem o ideal clássico do século XVII (AUBRIT, 2006).

Escrito em prosa e seguido por duas moralidades em verso, "Barba Azul" traz em seu incipit a fórmula clássica "era uma vez", anunciando o deslocamento do mundo racional para o mundo da fantasia e das histórias imemoriais. O conto narra a história de um homem muito rico que propõe casamento a qualquer uma das duas belíssimas filhas de uma dama viúva de família nobre. $\mathrm{O}$ aspecto feio e terrível conferido pela barba azul e o fato de já ter sido casado com outras mulheres cujo paradeiro era desconhecido pesaram na relutância das moças em aceitá-lo como marido. Mãe e filhas foram convidadas a visitar uma das casas de campo de Barba Azul, em companhia de amigas e rapazes da vizinhança. Após oito dias inteiros de "passeios, caçadas e pescarias, danças e festins, ceias" (PERRAULT, 2007, p. 95), a filha caçula concorda com o pedido. Um mês depois do casamento, Barba Azul parte em viagem e deixa as chaves de todos os cômodos com a esposa. Só a proíbe ameaçadoramente de abrir um certo aposento. Não resistindo à curiosidade, ela entra no gabinete proibido e descobre os corpos de várias mulheres mortas degoladas. Em choque, deixa cair a chave no chão ensanguentado e tenta em vão limpar a mancha de sangue indelével. Barba Azul volta na mesma noite, logo descobre a desobediência da esposa e declara que vai matá-la. A esposa ganha tempo pedindo para rezar, mas na verdade pergunta à sua irmã Ana, que está no alto de uma torre, se os seus irmãos estão chegando para salvá-la. Os dois cavalheiros chegam e matam o terrível esposo. Herdeira de toda a riqueza de Barba Azul, a viúva usa o 
dinheiro para ajudar sua família e se casar com um bom homem para esquecer o primeiro casamento.

Da literatura do século XVII para os primeiros tempos da história do cinema, seguimos o nosso percurso com a narrativa cinematográfica silenciosa do conto na visão de Georges Méliès.

\section{A BARBA AZUL EM BRANCO E PRETO}

Entre os mais de trinta títulos de "Barba Azul" que constam em Internet Movie Database (IMDb), optamos por trabalhar com o mais antigo: o filme mudo de Georges Méliès, de 1901. Escolhemos um diretor mítico do chamado cinema dos primeiros tempos (entre 1895 e 1910), segundo Gaudreault (2008), com o intuito de proporcionar uma experiência estética nova para a maior parte dos estudantes.

Muito diferente do cinema atual, os filmes mudos da época identificavam-se com o teatro, o circo, o espetáculo de mágica, a atração de quermesse. Méliès produziu artesanalmente mais de 100 filmes sobre temas diversos, entre 1896 (ano seguinte à invenção do cinema) e 1913, sendo Viagem à Lua (1902) o mais conhecido. Adepto da experimentação de novas técnicas, criador do primeiro estúdio de cinema, dono da Star Films fundada em 1896, Méliès é considerado precursor dos story boards, dos efeitos especiais e da montagem. Ele foi diretor, roteirista e protagonista de todas as suas produções, sendo também criador dos cenários e figurinos, inventor de trucagens (SADOUL, 1962, p. 9).

Barba Azul (1901) tem dez minutos de duração, contrastando com a maior parte dos filmes da época que duravam dois minutos em função das exigências dos exibidores, os quais queriam sessões rápidas para garantir uma alta rotatividade de espectadores.

O filme começa com um cenário que sugere o espaço de um palacete, e, no centro do plano, um personagem bufão e extravagante, vestido com roupas de época, fazendo reverências, cumprimenta os convidados. Moças, aparentemente bem mais jovens do que o homem, reagem com desprezo à corte que ele lhes faz. Sem argumentos para conquistá-las, o personagem barbudo promove um desfile de objetos valiosos trazidos pelos criados. Um dos cavalheiros, seduzido pelas joias presenteadas à sua 
filha, cede ao bufão e a força a aceitar o casamento. Na sequência, o casamento é consumado na presença de dois tabeliões, seguido de um banquete pantagruélico em comemoração às bodas.

A cena seguinte mostra o dono da casa partindo para uma viagem, seguido de uma longa fila de criados com bagagens. Ele confia à esposa as chaves da casa. Entre elas, entrega-lhe uma grande chave e aponta para a porta à qual se destina, com gestos ameaçadores e insistentes, deixando clara a proibição de abri-la. Atormentada pela curiosidade e com a chave nas mãos, a mulher é observada por um diabrete. Porém, ela cede à curiosidade e entra no aposento escuro, o que muda o registro bem-humorado da narrativa. Ali encontra corpos de sete mulheres assassinadas e um machado com uma poça de sangue no chão. $\mathrm{O}$ diabrete reaparece enquanto a esposa tenta lavar a chave em uma tina, em um esforço inútil. Ela atira longe a chave, e o diabrete a torna enorme, do tamanho da esposa. Nesse momento, uma fada surge, dá explicações à jovem e restitui o tamanho da chave, desaparecendo em seguida.

A sequência seguinte mostra a esposa tendo um pesadelo com o diabrete, que faz surgir as mulheres assassinadas pairando sobre a cama dela e a imagem do marido ameaçador com a espada em punho; sete chaves pairam sobre a cama, em uma dança macabra. Nesse momento, a fada reaparece e expulsa o diabrete.

Barba Azul, ao chegar e encontrar a esposa tentando limpar a mancha indelével de sangue, toma-lhe a chave das mãos e a ameaça com a espada. Ela lhe implora o perdão, aponta para o céu, como se estivesse pedindo para rezar. Barba Azul aponta para a torre, e a esposa sobe as escadas. Lá encontra uma moça (só os leitores do conto saberão que se trata de sua irmã Ana) que, por duas vezes, faz um gesto de quem olha ao longe. Primeiro, ela nada vê, mas, na segunda vez, aponta para fora e acena com um lenço. Barba Azul vai atrás da mulher e a arrasta pelos cabelos escada abaixo. Quando está a ponto de matá-la, surgem dois rapazes (os irmãos na narrativa escrita), os quais lutam com ele e o trespassam com uma espada prendendo-o ao muro. O diabrete reaparece ao lado de Barba Azul, no entanto, a fada ressurge e o faz desaparecer. Enquanto a esposa é consolada, a fada ressuscita as mulheres mortas, que emergem do chão e apontam para Barba Azul. Com outro gesto, a fada chama sete rapazes que se ajoelham e beijam a mão das moças. E então saem aos pares, em fila, seguidos pela esposa. Barba Azul observa tudo, esbravejando, até que o rapaz que o espetara recupera 
sua espada, fazendo com que ele finalmente caia morto. A última cena mostra grande parte do elenco sentada, tendo ao centro a esposa. Diante deles, jaz o corpo inerte de Barba Azul. Happy end para a heroína.

Vistas as narrativas literária e fílmica de "Barba Azul", é tempo de abordar o conceito de intermidialidade.

\title{
5. A TRANSPOSIÇÃO MIDIÁTICA: UM CONCEITO-CHAVE
}

Na leitura da BNCC de 2018, verificamos que uma das habilidades a ser desenvolvida no Ensino Médio é a da "análise contextualizada de produções artísticas e dos textos literários, com destaque para os clássicos” (BRASIL, 2018, p. 503).

Torna-se necessária, portanto, uma fundamentação teórica para que os futuros formadores vindos da dupla licenciatura em Letras e LE sejam capazes de produzir essa "análise contextualizada" de fenômenos intermidiáticos, como a adaptação cinematográfica de textos literários.

Escolhemos a perspectiva associada aos campos de estudos literários e intermidialidade de Irina Rajewsky (2012) como primeiro referencial teórico para iniciar os aprendizes nos estudos da adaptação enquanto transformação de mídia, em função de sua clareza e objetividade.

A autora define "a intermidialidade como uma categoria para a análise concreta de textos ou de outros tipos de produtos das mídias" (RAJEWSKY, 2012, p. 23), propondo uma concepção baseada nos Estudos Literários, mas não exclusiva a eles:

\begin{abstract}
A intermidialidade pode servir antes de tudo como um termo genérico para todos aqueles fenômenos que (como indica o prefixo inter-) de alguma maneira acontecem entre as mídias. "Intermidiático", portanto, designa aquelas configurações que têm a ver com um cruzamento de fronteiras entre as mídias e que, por isso, podem ser diferenciadas dos fenômenos intramidiáticos assim como dos fenômenos transmidiáticos, por exemplo, o aparecimento de um certo motivo, estética ou discurso em uma variedade de mídias diferentes. (RAJEWSKY, 2012, p. 18).
\end{abstract}

Rajewsky se concentra "nas configurações midiáticas concretas e em suas qualidades intermidiáticas específicas" (2012, p. 23), destacando uma variedade de manifestações intermidiáticas (romantizações, écfrase, quadrinhos, teatro, ópera, 
ilustrações de livros, poesia visual, entre outras), além das adaptações cinematográficas de obras literárias, que são comparáveis apenas em um sentido mais amplo. Essas especificidades permitem que ela estabeleça três subcategorias individuais de intermidialidade com concepções diferentes e mais restritas.

As subcategorias são transposição midiática, combinação de mídias e referências intermidiáticas. ${ }^{4}$ A transposição midiática, que abrange a adaptação cinematográfica e interessa a este artigo, entre outros fenômenos intermidiáticos,

[...] tem a ver com o modo de criação de um produto, isto é, com a transformação de um determinado produto de mídia (um texto, um filme, etc.) em outra mídia. Essa categoria é uma concepção de intermidialidade "genética" voltada para a produção: o texto ou o filme "originais" são a "fonte" do novo produto da mídia, cuja formação é baseada num processo de transformação específico da mídia e obrigatoriamente intermidiático (RAJEWSKY, 2012, p. 24).

Conforme Diniz (2018), a transposição midiática amplia os estudos da adaptação cinematográfica, foco recorrente dos Estudos Literários. A importância desse fenômeno intermidiático estende-se à indústria cinematográfica. De acordo com o relatório de 2018, Publishing's contribution to the wider creative industries da Publishers Association do Reino Unido, os roteiros baseados em livros faturam mundialmente 53\% a mais do que os roteiros originais. Além disso, eles têm melhor desempenho particularmente em termos da crítica, com histórias mais consistentes, cujo sucesso leva ao aumento na vendagem dos livros que os originaram.

Levantamos aqui algumas modificações acarretadas pelo processo de transposição midiática de "Barba Azul" de Perrault para o filme de Méliès e que se mostram relevantes para os estudos da intermidialidade. Duas passagens do conto enfatizam a fortuna de Barba Azul: a agradável estadia na casa de campo que acabou por convencer a filha mais nova da Dama que o pretendente "não tinha mais a barba tão azul e que era um homem de bem" (PERRAULT, 2009, p. 95-96) e a longa enumeração com a descrição das riquezas da casa no momento em que as vizinhas e boas amigas percorrem todos os aposentos, aproveitando a ausência do dono da casa a quem temiam. Com humor, Méliès ressignifica essa ostentação através do cenário (casa com pilares, lustres, decorações, guardas e sobretudo com a presença de muitos servos). Na sequência inicial, em substituição à temporada com a família da futura noiva e alguns 
jovens na casa de campo, Barba Azul recebe em sua casa convidados distintos e convoca seus criados a trazer uma grande bandeja com objetos etiquetados com cifras de muitos zeros e um grande porta-joias. Na passagem de Barba Azul com a noiva pela cozinha (inexistente no conto) há duas filas de ajudantes carregando os pratos fartos de um banquete pantagruélico e uma enorme garrafa do champagne Mercier (fundado em 1895), detalhe anacrônico e bem-humorado que prenuncia o merchandising no cinema. Na partida para a viagem de negócios, o acréscimo de uma fila indiana de criados segue seu senhor carregando-lhe as bagagens. As enumerações das riquezas do texto literário foram substituídas pela fila de servos.

Voltamos ao texto de Rajewsky (2012) no que tange à recepção da transposição durante a visualização do filme: o espectador recebe o texto literário original a partir das diferenças e equivalências em relação à adaptação.

\begin{abstract}
Essa recepção ocorre não (apenas) devido a um conhecimento anterior ou à bagagem cultural que o espectador possa ter, mas por causa da própria constituição específica do filme. Abrem-se, assim, camadas adicionais de sentidos que são produzidos especificamente pelo ato de se referir, ou de relacionar, filme e texto. Em vez de ser simplesmente baseada numa obra literária original preexistente, uma adaptação pode, então, constituir-se em relação à obra literária, caindo assim na categoria das referências intermidiáticas (RAJEWSKY, 2012, p. 26; grifo da autora).
\end{abstract}

Observamos também a forte presença do teatro no cinema de Méliès pelo uso da câmera fixa em todos os planos do filme, sem mudança de ponto de vista e em posição frontal, imitando o olhar do espectador de teatro. Sem qualquer menção escrita contendo as informações que geralmente constituem as aberturas fílmicas, surge o primeiro quadro (BEAUREGARD, 2017), denominação que se dá aos planos longos e ininterruptos que se sucedem em um único cenário, onde os atores aparecem sempre de corpo inteiro. Cada ação se esgota dentro do quadro. A transição entre os quadros se dá através do crossfade, técnica de montagem em que uma imagem desaparece progressivamente enquanto a imagem seguinte vai aparecendo; como resultado, por alguns instantes, as duas imagens se sobrepõem.

Assim, o filme de Méliès é plurimidiático pela presença do teatro e de outras mídias - números de mágica, teatro de marionetes, atrações de quermesse -, responsáveis pela dimensão espetaculosa e muitas vezes burlesca dada pelas trucagens, explosões esfumaçadas, comicidade, acrobacias, e muitos figurantes. É o caso das 
sequências da passagem pela cozinha com imagens de pastelão, da hesitação da esposa em abrir o aposento proibido e da descoberta do segredo de Barba Azul (em que ela é acompanhada por um diabrete e salva por uma fada), do pesadelo com as imagens flutuantes do corpo das esposas assassinadas, do Barba Azul e das chaves gigantes. Como grand finale das técnicas exploradas no filme, destacamos o último quadro, com uma fila das mulheres mortas que brotam do chão ressuscitadas pela fada saída de um poço e acompanhadas por jovens, (prováveis futuros maridos), vindos de não se sabe onde, além da viúva e sua família. A comemoração termina com o içamento do cenário, que dá lugar a um palco, de maneira a produzir um distanciamento dos códigos cinematográficos, em mais uma referência ao teatro.

Segundo Rajewsky (2012), esse tipo de referenciação caracteriza a remediação, um tipo particular de referência intermidiática que se dá através da apropriação, da remodelação das práticas representativas de mídias mais antigas. No caso do cinema que remediou as práticas teatrais desde sua origem em busca de reconhecimento, em termos culturais, trata-se de uma remediação do ponto de vista genealógico que ocorre de modo geral. Quanto aos números de mágica, teatro de marionetes e atrações de quermesse, trata-se de remediação em uma configuração midiática individual, ou seja, o cinema de Georges Méliès, mágico, prestidigitador famoso com formação em Londres e larga experiência nos palcos. Méliès buscava produzir em seu estúdio um espetáculo inventivo com simulacros e trucagens, diferente do espelho da realidade que buscavam os irmãos Lumière, inventores do cinematógrafo (BEYLIE, 2021).

Passaremos agora à proposta de uma sequência didática para o estudo de Barba Azul (1901) para os estudantes em Letras que não envolverá uma avaliação em termos de uma adaptação bem-sucedida ou fiel ao conto, mas antes uma perspectiva analítica da transformação do texto literário, "uma discussão entre semelhanças e diferenças entre produtos de mídia sem normatização", lembrando que "o ato de transmidiar, transformar e adaptar têm em comum o fato de envolverem a permanência e a exclusão de alguns dos elementos e a inclusão de algo novo" (ELLESTRÖM, 2017, p. 178).

\section{UMA INTRODUÇÃO À INTERMIDIALIDADE EM CURSOS DE LETRAS}


Atividades com foco nas diferentes configurações midiáticas de uma obra literária podem ser propostas no âmbito das disciplinas que contemplam o estudo da literatura, abordando respectivamente a narrativa curta, o romance, a poesia e o teatro, cultura e civilização e também em disciplinas de ensino da língua estrangeira.

Escolhemos a sequência didática, definida como "um conjunto de atividades escolares organizadas de maneira sistemática, em torno de um gênero textual oral ou escrito" (DOLZ; NOVERRAZ; SCHNEUWLY, 2004, p. 82) com o objetivo de iniciar os estudantes nos estudos da intermidialidade, mais especificamente na apropriação do conceito de transposição intermidiática. Embora tenhamos trabalhado com vários materiais em língua francesa, utilizamos a tradução do conto para o português para estimular a adaptação deste trabalho para outras licenciaturas duplas. Em se tratando de um conto célebre como "Barba Azul" de Perrault, é possível encontrar materiais equivalentes, amplamente disponibilizados na internet nas diferentes línguas estrangeiras.

Optamos pelo foco na primeira etapa da construção da sequência didática, a “apresentação da situação" (DOLZ; NOVERRAZ; SCHNEUWLY, 2004, p. 84) na qual os aprendizes devem perceber a importância dos conteúdos com os quais vão trabalhar em futuras produções, com ênfase nos conhecimentos prévios dos estudantes e no incentivo à explicitação verbal. Parece-nos fundamental que a descoberta da intensa reativação da obra literária canônica em diferentes épocas e mídias estimule os futuros formadores a trabalhar com o viés da intermidialidade para atrair os jovens leitores com os quais trabalharão.

As etapas da sequência didática em torno de "Barba Azul" (1697) e sua transposição midiática para o cinema Barba Azul (1901) são:

1) Pré-leitura de Barba Azul (1697)

2) Leitura de Barba Azul (1697)

3) Pré-visualização de Barba Azul (1901)

4) Produção de uma escaleta

5) Visualização de Barba Azul (1901)

6) Discussão entre os estudantes

Uma das razões da nossa opção por um filme mudo, com planos longos, atores mostrados sempre de corpo inteiro e duração de dez minutos, para a análise da 
transposição midiática de "Barba Azul" nessa sequência didática foi a possibilidade de prescindirmos de elementos teóricos relativos à análise cinematográfica. Embora o cinema dos primeiros tempos seja objeto de muitos estudos teóricos, a câmera parada de Barba Azul (1901) nos permitiu focalizar nos aspectos descritivos e criativos da imagem, e na análise da narrativa. Introduzimos apenas alguns termos especializados, como escaleta, transição em crossover e close-up.

Quanto ao referencial teórico sobre a intermidialidade, escolhemos a perspectiva associada aos campos de estudos literários e intermidialidade de Irina Rajewsky (2012) como primeiro referencial teórico para iniciar os aprendizes nos estudos da adaptação enquanto transformação de mídia, em função de sua clareza e objetividade.

A etapa de pré-leitura do conto, que será lido em LE, compreende uma discussão em que o aprendiz possa falar de seus saberes, de seu horizonte de expectativas. Além disso, os aprendizes podem realizar leituras que os ajudem a enriquecer e/ou tomar contato com a leitura do conto de fadas de 1697 e, ao mesmo tempo, reativar o seu significado no momento atual.

As questões que orientam uma primeira discussão são:

1) Você conhece algum conto de fadas? Qual?

2) Se sua reposta anterior foi afirmativa, como foi o contato (livro, filme, série, game etc.)?

3) Pode citar algum produto de mídia que evoca contos de fadas ou seus personagens?

4) Conhece ou já ouviu falar no personagem "Barba Azul"?

5) Se sim, lembra-se de alguma passagem do conto?

Nesta discussão espera-se que o aprendiz ative mais uma vez o seu conhecimento enciclopédico e cite alguma das adaptações de contos de fadas popularizadas no cinema, em séries televisivas, HQ, games etc. $^{5}$

Após dar voz à experiência dos estudantes como leitores de contos de fadas em diferentes mídias, será solicitada uma busca de informações sobre os contos de fadas e Charles Perrault no contexto do século XVII. ${ }^{6}$

Em seguida, convidaremos os estudantes a folhear as páginas de "Barba Azul" observando sua organização tipográfica. O aprendiz entra em contato com o universo interno da narrativa, que apresenta desde as notas de rodapé com explicações de 
vocabulário, passando pelo incipit que começa com a formulação "Il était une fois" (era uma vez), o texto condensado em prosa e com fragmentos entre aspas representando o discurso direto, a presença de maiúsculas em determinados substantivos até as duas moralidades em verso - Moralité e Autre Moralité. Para concluir a etapa da pré-leitura, propomos um debate em torno do horizonte das expectativas criadas: é possível antecipar a trama de "Barba Azul" de Perrault? Quem é Barba Azul? Qual a razão de existirem duas moralidades?

Segue-se a etapa da leitura do conto, que confirma as hipóteses levantadas pelos estudantes ou lhes revela um novo horizonte de narrativa. Essa fase deve incitar uma nova discussão a partir do que foi imaginado e do que realmente acontece na narrativa, levando os estudantes a utilizar o conhecimento que adquiram a partir da busca efetuada sobre contos de fadas e Charles Perrault.

Em seguida, é solicitado o preenchimento de um quadro sinóptico (Figura 1) contendo elementos essenciais do conto para a reflexão sobre a transposição para o cinema mudo realizada por Méliès:

\begin{tabular}{|l|l|}
\hline 1) Etapas da narrativa & \\
\hline $\begin{array}{l}\text { 2) Presença de objetos mágicos } \\
\text { característicos do conto maravilhoso }\end{array}$ & \\
\hline 3) Personagens & \\
\hline 4) Tempo & \\
\hline 5) Espaço & \\
\hline 6) Moral (duas) & \\
\hline
\end{tabular}

Figura 1 - Quadro sinóptico sobre o conto. Fonte: elaborada pelas autoras, 2021

Em seguida, passamos à etapa das atividades de pré-visualização de Barba Azul (1901), em que apresentaremos dois curtos documentários (Georges Méliès, o Mágico do cinema e IL ÉTAIT UNE FOIS... Georges Méliès, cinémagicien), o thriller e a sequência Tribute scene de A invenção de Hugo Cabret (2011), de Martin Scorsese, e dois clips com referências às imagens dos filmes de Méliès (Haven for Everyone, do Queen, e Tonight, Tonight, do The Smashing Pumpkins), todos disponíveis no YouTube. 
Após a visualização desses documentos, os estudantes serão incentivados a comentá-los livremente, sem um trabalho específico sobre cada um deles. Pretendemos proporcionar um momento lúdico aos jovens que, muito provavelmente, nunca ouviram falar de Georges Méliès, nem assistiram a filmes mudos. Esta é uma etapa que visa sensibilizar o aprendiz para uma das características de obras clássicas como os filmes de Méliès e o "Barba Azul" de Perrault que continuam a ser uma referência importante na atualidade e, "em sua trajetória até a recepção contemporânea, mantiveram-se reiteradamente legitimadas como elemento expressivo de suas épocas" (BRASIL, 2018, p. 523).

A quarta etapa da nossa sequência didática começará pela leitura em grupo do texto "Intermidialidade, intertextualidade e 'remediação': uma perspectiva literária sobre a intermidialidade" de Irina Rajewsky (2012), seguida de uma discussão em grande grupo sobre as três subcategorias individuais de intermidialidade propostas pela autora, a transposição midiática, a combinação de mídias e as referências intermidiáticas.

Criado um horizonte de expectativas a partir da leitura do conto e do texto teórico, e da visualização do material do YouTube, os estudantes, em dupla, devem redigir uma escaleta ou outline (SALLES, 2009), etapa pré-roteiro de uma adaptação do "Barba Azul" para o cinema mudo. Mais simples do que o roteiro, a escaleta pode ter a forma de um curto resumo do roteiro dividido em sequências com a ação e os personagens correspondentes. O aprendiz deve ter em seu horizonte que o filme de Méliès dura 10 minutos e que dispõe da liberdade para introduzir modificações na história.

Ao tomar o filme de Méliès como um produto fruto de uma transposição midiática, o aprendiz compreende que o processo de transformação "tem a ver com o modo da criação do produto de mídia" (RAJEWSKY, 2012). Nesse sentido, fica mais claro perceber que a versão fílmica está ligada a uma concepção genética em que o conto de Perrault representa apenas a fonte do novo produto de mídia. Partindo dessa perspectiva, o aprendiz entende que o filme está intimamente ligado ao conto mas que não apresenta nenhuma dependência do texto fonte para a formação completa de sentido. 
Em seguida, as duplas devem apresentar as escaletas produzidas em uma discussão em grande grupo. Este momento se revela importante, pois os estudantes expõem o motivo pelo qual decidiram o modo como transpuseram o conto para um novo produto de mídia. Neste momento, é possível notar como a teoria abordada sobre transposição de mídia ajuda o aprendiz a fazer determinadas escolhas.

$\mathrm{Na}$ etapa de visualização, o filme de Georges Méliès será exibido duas vezes. Depois da primeira apresentação, os estudantes emitem suas impressões de modo livre. Em seguida, o filme é apresentado uma segunda vez, e os aprendizes devem completar a segunda coluna de um quadro sinóptico para o estudo comparativo das etapas das narrativas literária e fílmica (Figura 2).

\begin{tabular}{|l|l|}
\hline \multicolumn{1}{|c|}{ LITERÁRIA } & \multicolumn{1}{c|}{ FÍLMICA } \\
\hline Apresentação dos personagens e contexto. & Busca de uma noiva. Casamento civil. \\
\hline Viagem de oito dias à casa de campo. & Passagem pela cozinha. \\
\hline Casamento. & Jantar de casamento. \\
\hline Viagem de Barba Azul e entrega das chaves. & Viagem de Barba Azul e entrega das chaves. \\
\hline Hesitação. Transgressão da proibição. & Hesitação. Transgressão da proibição. \\
\hline Descoberta das esposas mortas. & Descoberta das esposas mortas. \\
\hline- & Pesadelo da Esposa. \\
\hline Retorno do marido. & Retorno do marido. \\
\hline Ameaças de morte. & Ameaças de morte. \\
\hline Subida da esposa para seus aposentos. Apelos à & Subida da esposa à torre. Apelos à irmã Ana. \\
irmã Ana. & \\
\hline- & Subida de Barba Azul à torre. \\
\hline Chegada dos irmãos. Morte de Barba Azul. & Descida do casal. Chegada dos espadachins. \\
\hline Final feliz. & Morte de Barba Azul. \\
\hline Moralidades dissonantes. & Final Feliz. \\
\hline
\end{tabular}

Figura 2 - Quadro sinóptico: Estudo comparativo das etapas das narrativas literária e fílmica. Fonte: elaborado pelas autoras, 2021.

A etapa final prevê uma discussão entre os estudantes, a partir das informações inseridas no quadro comparativo. Debatermos as diferenças e semelhanças das narrativas e o modo como elas são desenvolvidas em cada produto de mídia. O 
aprendiz, após esse percurso, é capaz de perceber que a narrativa do conto foi adaptada de maneira a restituir basicamente as mesmas etapas, com substituições, exclusões e acréscimos explicados pela natureza da nova mídia, pelas limitações técnicas dos primeiros tempos do cinema mudo. Os saberes ligados ao contexto social, o conjunto das obras literárias e cinematográficas no mesmo momento histórico e a expressão da criação individual de Georges Méliès são ressaltados neste momento.

\section{CONSIDERAÇÕES FINAIS}

Este artigo defende a necessidade da inclusão de estudos do campo da intermidialidade nos currículos das Licenciaturas em Letras. Esta proposta está alicerçada em um pilar tríptico:

1) Proporcionar ao aprendiz um letramento no campo da intermidialidade e das novas mídias;

2) Tornar o aprendiz apto a realizar a análise de novas configurações textuais produzidas em diversos produtos de mídia por diferentes modos de apropriação dos textos literários, de maneira fundamentada conforme preconiza a Base Nacional Comum Curricular de 2018;

3) Preparar futuros formadores para a evolução dos paradigmas educacionais em função das profundas transformações sociais e tecnológicas de nosso tempo.

Com este horizonte, uma sequência didática é proposta para iniciar o aprendiz na prática da leitura de transposições midiáticas de textos literários para o cinema, oferecendo estratégias e fundamentação teórica para a sua futura prática docente. Para tal, optou-se pelo texto literário "Barba Azul" (1697), conto de Charles Perrault, e sua adaptação Barba Azul (1901) por Georges Méliès. Essa escolha foi norteada pela importância dos contos de fada na constituição e formação do indivíduo e pelo desejo de introduzir o cinema mudo de Méliès no horizonte do aprendiz.

Acreditamos que esta proposta, ao partir da orientação da Base Nacional Comum Curricular de 2018, oferece grande potencial ao conjugar textos imaginados "antigos" e "envelhecidos" com descobertas de novos produtos midiáticos e seus estudos a partir do campo da intermidialidade. Como resultado, o aprendiz é letrado em 
um novo campo de estudo, o da intermidialidade, e se torna testemunha de um novo texto literário, que ganha outro frescor. A partir dessa experiência, o aprendiz encontra ferramentas para se tornar um novo formador.

\section{Referências}

AUBRIT, J-P. Le Conte et la nouvelle. Paris: Armand Colin/Masson, 2006.

BARBE BLEUE. Direção de Georges Meliès. Montreuil-sous-Bois: Star Films, 1901. (10 min.). Disponível em: https://www.youtube.com/watch?v=gg_nWW-TgFg\&t=25s. Acesso em: 11 mar. 2020.

BEAUREGARD, P. Le montage chez Méliès. "Blog Cinéphil", 16 jan. 2008. Disponível em: http://cinephil.centerblog.net/3663194-Le-montage-chez-Melies. Acesso em: 15 jul. 2020.

BEYLIE, C. "MÉLIÈS GEORGES (1861-1938)", Encyclopadia Universalis [en ligne]. s/d. Disponível em: https://www.universalis.fr/encyclopedie/georges-melies/. Acesso em: 7 dez. 2020.

BRASIL. Ministério da Educação. Parâmetros Curriculares Nacionais para o Ensino Médio. Parte II: Linguagens, Códigos e suas Tecnologias. Brasília: MEC/SEMTEC, 2000. Disponível em: http://portal.mec.gov.br/seb/arquivos/pdf/14_24.pdf. Acesso em: 4 set. 2020.

CNE/CSE Ministério da Educação. Diretrizes Curriculares do Curso de Letras. Brasília http://portal.mec.gov.br/cne/arquivos/pdf/CES0492.pdf. Acesso em: 9 ago. 2020.

. Ministério da Educação. Orientações Curriculares do Ensino Médio. Volume 1: Linguagens, Códigos e suas Tecnologias. Brasília: MEC/SEB, 2006. Disponível em: http://portal.mec.gov.br/seb/arquivos/pdf/book_volume_01_internet.pdf Acesso em: 15 ago. 2020.

\begin{tabular}{ccccc}
\multicolumn{2}{c}{ Ministério da Educação. Base } & Nacional Comum & Curricular. Ensino Médio. \\
Brasília: & MEC/SEM/CNE, & 2018. & Disponível & em:
\end{tabular} http://basenacionalcomum.mec.gov.br/wpcontent/uploads/2018/11/7._Orienta\%C3\%A7\%C3\%B5es_aos_Conselhos.pdf. Acesso em: 20 ago. 2020.

DOLZ, J.; NOVERRAZ, M.; SCHNEUWLY, B. "Sequências didáticas para o oral e a escrita: apresentação de um procedimento". In: SCHNEUWLY, B.; DOLZ, J. (Orgs). Gêneros orais e escritos na escola. Campinas: Mercado das Letras, 2004. p. 81-108. 
DINIZ, T. F. N. Intermidialidade: perspectivas no cinema. RuMoRes, Dossiê, v. 12, n. 24, p. 41-60, 2018. Disponível em: https://www.revistas.usp.br/Rumores/article/view/143597. Acesso em: 25 fev. 2021.

ELLESTRÖM, L. “Adaptação no campo das transformações das mídias”. Tradução de Ana Claudia Munari Domingos. In: ELLESTRÖM, L. Midialidade. Ensaios sobre Comunicação, Semiótica e Intermidialidade. Organização de Ana Claudia Munari Domingos, Ana Paula Klauck e Glória Maria Guiné de Mello. Porto Alegre: EDIPUCRS, 2017. p. 175-198.

FAILLA, Z. "Introdução. O retrato do comportamento leitor do brasileiro". In: FAILLA, Z. (Org.). Retratos da leitura no Brasil 5. Rio de Janeiro: Sextante, 2021. p. 21-41. Disponível em: https://www.prolivro.org.br/5a-edicao-de-retratos-da-leitura-nobrasil-2/principal-do-livro/download/ Acesso em: 15 jul. 2021.

FUSILLO, M. Hybrid Transitions. Comparative Literature and Visual Culture. Revue de littérature comparée, vol. 348, n. 4, p. 413-421, 2013. Disponível em: https://www.cairn.info/revue-de-litterature-comparee-2013-4-page-413.htm. Acesso em: 18 set. 2019.

GAUDREAULT, A. Cinéma et attraction - Pour une nouvelle histoire du cinématographe. Paris: CNRS Éditions, 2008.

INTERNET MOVIE DATABASE. Disponível em: https://www.imdb.com/find?s=tt\&q=Barbe+bleue\&ref_=nv_sr_sm. Acesso em: 20 ago. 2020.

KEHL, M. R. “A criança e seus narradores. Prefácio.” In: CORSO, D. L.; CORSO, M.. Fadas no divã. Psicanálise nas histórias infantis. São Paulo: Artmed, 2006. p. 15-19.

PERRAUlT, C. "Barba azul". In: Contos e Fábulas. Charles Perrault. Tradução e posfácio de Mário Laranjeira. Ilustrações Fê - [3. Reimp.] São Paulo: Iluminuras, 2007. p. 95-99.

PERRAUlt, C. Contes de ma Mère l'Oye. Dossier par Hélène Tronc. Gravures de Gustave Dorée. Lecture d'image par Valérie Lagier. Col. Folioplus. Paris: Gallimard, 2006.

PUBLISHERS ASOCIATION UK. Publishing's contribution to the wider creative industries. A report prepared for the Publishers Association. July 2018. Disponível em: https://www.creativeindustriesfederation.com/publications/publishings-contributionwider-creative-industries. Acesso em: $20 \mathrm{dez} .2020$.

RAJEWSKY, I. O. “Intermidialidade, intertextualidade e 'remediação': uma perspectiva literária sobre a intermidialidade". Tradução de Thaïs Flores Nogueira Diniz e Eliana Lourenço de Lima Reis. In: DINIZ, T. F. N. (Org.). Intermidialidade e estudos interartes: desafios da arte contemporânea. Belo Horizonte: Editora UFMG, 2012. p. $15-45$. 
RAMAZZINA-GHIRARDI, A. L. Letramento literário multimodal e intermidiático: a construção do leitor/scriptor de uma nova mídia. Linha D'Água (Online), São Paulo, v. 30, n. 2, p. 51-69, out. 2017. Disponível em: https://www.revistas.usp.br/linhadagua/article/view/131654/135264. Acesso em: 18 ago. 2020.

RAMAZZINA-GHIRARDI, A. L. Intermidialidade e transdisciplinaridade na formação de um leitor proficiente. Todas as Letras, São Paulo, v. 20 n.1, p. 80-92, jan./abr. 2018. Disponível em: http://editorarevistas.mackenzie.br/index.php/tl/article/view/10771/7145 Acesso em: 18 ago. 2020.

RAMAZZINA-GHIRARDI, A. L. e LACELLE, N. (orgs.). Vers les productions multimodales et intermédiales. Synergies Brésil, Revue du Gerflint, n. 13, 2018. Disponível em : http://gerflint.fr/Base/Bresil13/bresil13.html. Acesso em: 18 ago. 2020.

RAMAZZINA-GHIRARDI, A. L., PINHEIRO, E.M. Le Petit Prince e multimodalidade: linguagem literária, quadrinhos, novos leitores. Building the way (Revista do Curso de Letras da Universidade Estadual de Goiás), v. 10, n. 1, junho $2020 . \quad$ Disponível em: https://www.revista.ueg.br/index.php/buildingtheway/article/view/10474. Acesso em: 14 jul.2021.

SALLES, D. L'adaptation cinématographique d'œuvres littéraires. Cinéma Audiovisuel de l'Académie de Grenoble. 06/01/2009. Disponível em: http://www.acgrenoble.fr/audiovisuel/articles.php?lng=fr\&pg=57. Acesso em: 6 mar. 2021.

SADOUL, G. Le Cinéma français. Paris: Flammarion, 1962.

ZIPES, J. Un remake de La Barbe bleue, ou l'au-revoir à Perrault. Féeries [En ligne], 8 /2011, mis en ligne le 15 avril 2013. Disponível em: http://journals.openedition.org/feeries/779 . Acesso em: 20 set.2020.

Recebido em: 05/05/2021

Aceito em: 11/08/2021

\footnotetext{
${ }^{1}$ Citando apenas adaptações do cinema mainstream, sem mencionar os filmes de animação: Alice no País das maravilhas (2010), de Tim Burton; A Garota da Capa Vermelha (2011), de Catherine Hardwicke; A Fera (2011), de Daniel Barnz; Espelho, espelho meu (2012), de Tarsem Singh; Branca de Neve e o Caçador (2012), de Rupert Sanders; João e Maria caçadores de Bruxas (2013), de Tommy Wircola; Malévola (2014), de Robert Stromberg; Cinderela (2015), de Kenneth Branagh; Peter Pan (2015), sob a direção de Joe Wright; e A Bela e a Fera (2017), de Bill Condon.

2 Katia Canton (DCL, 2005), Anabella Lopez (Aletria, 2006), Monteiro Lobato (Companhia Editora Nacional, 2007), Mário Laranjeira (Iluminuras, 2007), Fernanda Lopes de Almeida (Ática, 2008), Hildegard Feist (Companhia das Letrinhas, 2009), Flávio de Souza (FTD, 2010), Ruth Rocha (Moderna, 2010), Maria Luiza Borges (Zahar, 2010), Ivone Benedetti (L\&PM, 2012), Antônio Klévisson Viana
} 
(Escala Educacional, 2012), Walcyr Carrasco (Manole, 2009 e Moderna, 2013), Leonardo Fróes (Cosac Naiff, 2015) e Eliana Bueno-Ribeiro (Paulinas, 2016).

${ }^{3}$ A psicanálise dos contos de fadas, de Bruno Bettelheim (1976); Mulheres que correm com os lobos (1992), de Clarissa Pinkola Estés; Os 7 pecados capitais nos contos de fadas: como os contos de fadas influenciam nossas vidas, de Sheldon Cashdan (2000) e Fadas no divãa: Psicanálise nas Histórias Infantis (2005), de Diana Lichtenstein Corso e Mário Corso; as recriações literárias Barba azul (2012), de Amélie Nothomb; O ovo do Barba Azul e outras histórias (2016), de Margaret Atwood; O quarto do Barba-Azul (2000), de Angela Carter; as reapresentações do balé Barba Azul (1977), de Pina Bausch e das óperas $O$ Castelo de Barba Azul (1911), de Bélla Bartók e Barba Azul, de Offenbach (1866).

${ }^{4}$ A segunda subcategoria, a combinação de mídias (ópera, filme, teatro, quadrinhos, etc.), diz respeito a configurações que são o produto da articulação de pelo menos duas mídias, sendo que cada uma está presente em sua materialidade e contribui para a constituição e o significado do produto. Na subcategoria das referências intermidiáticas (referência a filme ou pintura dentro de um texto literário, musicalização da literatura, écfrase), o produto da mídia remete a uma mídia de referência, através da tematização, imitação ou evocação de suas técnicas.

${ }^{5}$ Filmes como Alice no País das Maravilhas (2010), Rapunzel (2010), A Garota da Capa Vermelha (2011), A Fera (2011), Espelho, espelho meu (2012), Branca de Neve e o Caçador (2012), João e Maria caçadores de Bruxas (2013), Malévola (2014), Cinderela (2015), Peter Pan (2015), A Bela e a Fera (2017), Frozen (2019 e 2013). E também a saga de Harry Potter, conto de fadas moderno. Há também séries televisivas como Once upon a time (2011-2018), Grimm (2011- 2017), A Bela e a Fera (20122016) e Tell me a story (2018-2020). Quanto ao "Barba Azul", além das dezesseis publicações no mercado editorial brasileiro (traduções, recriações e reedições) que mencionamos anteriormente, também há games populares como Bluebeard Castle (2014) e The Wolf Among Us (2014).

${ }^{6}$ Para cursos de Letras Português/Francês, sugerimos as Gravuras de Gustave Dorée e os três textos do dossiê de Contes de ma Mère l'Oye (2006), de Charles Perrault, na coleção Folioplus Classiques da editora Gallimard: "La naissance du conte de fées littéraire", "L'écrivain à sa table de travail: du conte populaire au conte littéraire" e "Perrault et son temps". 